\title{
Antivenomics as a tool to improve the neutralizing capacity of the crotalic antivenom: a study with crotamine
}

Ricardo Teixeira-Araújo 1,2, Patrícia Castanheira', Leonora Brazil-Más², Francisco Pontes ${ }^{1,2}$, Moema Leitão de Araújo ${ }^{3}$, Maria Lucia Machado Alves ${ }^{3}$, Russolina Benedeta Zingali ${ }^{1}$ and Carlos Correa-Netto ${ }^{1,2^{*}}$

\begin{abstract}
Background: Snakebite treatment requires administration of an appropriate antivenom that should contain antibodies capable of neutralizing the venom. To achieve this goal, antivenom production must start from a suitable immunization protocol and proper venom mixtures. In Brazil, antivenom against South American rattlesnake (Crotalus durissus terrificus) bites is produced by public institutions based on the guidelines defined by the regulatory agency of the Brazilian Ministry of Health, ANVISA. However, each institution uses its own mixture of rattlesnake venom antigens. Previous works have shown that crotamine, a toxin found in Crolatus durissus venom, shows marked individual and populational variation. In addition, serum produced from crotamine-negative venoms fails to recognize this molecule.
\end{abstract}

Methods: In this work, we used an antivenomics approach to assess the cross-reactivity of crotalic antivenom manufactured by IVB towards crotamine-negative venom and a mixture of crotamine-negative/crotamine-positive venoms.

Results: We show that the venom mixture containing $20 \%$ crotamine and $57 \%$ crotoxin produced a strong immunogenic response in horses. Antivenom raised against this venom mixture reacted with most venom components including crotamine and crotoxin, in contrast to the antivenom raised against crotamine-negative venom.

Conclusions: These results indicate that venomic databases and antivenomics analysis provide a useful approach for choosing the better venom mixture for antibody production and for the subsequent screening of antivenom cross-reactivity with relevant snake venom components.

Keywords: Antivenom production, Antivenomics, Crotalus durissus, Crotamine, Crotoxin, Geographic venom variation

\section{Background}

For over a century, antivenoms have remained the only effective treatment for snakebite. An important technical consideration in the production of antivenoms is to use suitable mixtures of venoms (as antigens) in order to produce neutralizing antibodies against the venom of the intended species. Although antivenom administration constitutes an effective therapy against envenomation, the occurrence of inter- and intraspecies venom variability has

\footnotetext{
* Correspondence: netto@bioqmed.ufrj.br

'Laboratório de Hemostase e Venenos, Instituto de Bioquímica Médica Leopoldo de Meis, Universidade Federal do Rio de Janeiro (UFRJ), Rio de Janeiro, RJ, Brasil

'Departamento de Antígenos e Cultivo Celular, Instituto Vital Brazil, Niterói, RJ, Brasil

Full list of author information is available at the end of the article
}

led to the need for a more robust understanding of venom composition and antivenom efficacy.

The preparation of representative mixtures of venoms from snake species with a broad geographic distribution is not easy, particularly if there is no venomic-based assessment to facilitate the selection of appropriate venom-producing specimens $[1,2]$. In Brazil, six subspecies of Crotalus durissus are currently recognized (C. $d$. dryinas, $C$. d. marajoensis, C. d. ruruima, C. d. terrificus, C. d. cascavella, and C.d. collilineatus), with each inhabiting distinct ecosystems and displaying a wide geographical distribution [3-5]. All of these subspecies are capable of producing lethal envenomation in humans, since their venoms exhibit systemic neuro- and myotoxic activities.

Envenomation symptoms are often attributed to the presence of crotoxin and crotamine, although marked 
differences in the concentration of these toxins among venoms have been documented. For example, crotoxin, a neurotoxic phospholipase $\mathrm{A}_{2}\left(\mathrm{PLA}_{2}\right)$, is the main toxin of $C$. durissus venom and accounts for $70-90 \%$ of its venom proteome [6-10]. On the other hand, significant variation has been observed for crotamine at both individual and population levels, since it accounts from 2 up to $22 \%$ of $C$. durissus proteome $[9,11-13]$. There is also a positive correlation between the concentration of crotamine present in venom and the level of crotamine gene expression (ranging from 1 to 32 copies per haploid genome) [12].

The Vital Brazil Institute (IVB) is one of three Brazilian institutions that manufacture antivenoms, the others being the Butantan Institute and Ezequiel Dias Foundation (FUNED). Although the crotalic antivenom produced by the three institutions follows the guidelines defined by Brazilian National Health Surveillance Agency (ANVISA), each institution uses its own crotalic antigens. ANVISA has determined that immunization should use crotaminepositive venom obtained from specimens that cover the geographical distribution of C. durissus [5]. However, determination of the $\mathrm{LD}_{50}$ is the only quality control measure required for the venoms.

The use of antivenomics to evaluate antivenom efficacy was first described in an investigation of the immunoreactivity of the polyvalent antivenom produced by the Costa Rican Clodomiro Picado Institute (ICP) against Bothriechis lateralis and Bothriechis schlegelii venoms [14]. Subsequently, antivenomics has emerged as a logical extension of venomic studies and has been applied to numerous medically relevant species $[1,15,16]$. In addition, antivenomics protocols have been extensively revised and improved, and used in pre-clinical studies to assess the efficacy of antivenoms and their potential clinical applicability across the geographical range of a species [1, 2, 17-20].

In a previous study, we applied a first generation antivenomics approach to examine the immunoreactivity of crotalic antivenom against subspecies of Brazilian rattlesnakes. The results indicated that the crotalic antivenom was devoid of antibodies capable of recognizing and binding to crotamine [9]. This finding suggested either that the venom used in the production of the crotalic antivenom was devoid of crotamine, or that the low molecular mass of crotamine $(4.8 \mathrm{kDa})$ meant that this cationic polypeptide could be a poor immunogen in horses. In order to explore further this question, the current study applied a second generation of antivenomics approach to examine the cross-reactivity of the crotalic antivenom produced at IVB using a pool of crotamine-negative and crotamine-positive venoms. Our results showed that using the proper immunogenic pool, all components from Crotalus venom can be recognized.

\section{Material and methods}

\section{Venoms and antivenoms}

The venoms of $C$. $d$. terrificus were obtained from captive specimens maintained at the Regional Ophiology Center of Porto Alegre (NOPA) and IVB. Crotaminepositive venom (batch 2014CDU00301) was extracted from 26 adult specimens (10 males and 16 females) housed at NOPA. These snakes were collected primarily in Protásio Alves city, in the southern Brazilian state of Rio Grande do Sul. Crotamine-negative venom (batch 2014CDU00201) was extracted from 44 adult specimens of both genders maintained by IVB. The latter snakes were originally collected near Juiz de Fora in the state of Minas Gerais. Following venom extraction, samples were centrifuged at $1000 \mathrm{~g}$ to remove cell debris, lyophilized and stored at $-20{ }^{\circ} \mathrm{C}$.

In accordance with the guidelines of the Brazilian Pharmacopeia [21], and before preparing the mixture of venoms for immunization, the median lethal doses $\left(\mathrm{LD}_{50}\right)$ for the crotamine-positive (batch 2014CDU00301) and crotamine-negative (batch 2014CDU00201) venoms were determined as a quality control. The data available from internal registers of IVB indicated an $L_{50}$ of $153 \mu \mathrm{g} / \mathrm{kg}$, accessed via intraperitoneal (i.p.) route, for the crotamine-positive venom (batch 2014CDU00301) and an $\mathrm{LD}_{50}$ of $73 \mu \mathrm{g} / \mathrm{kg}$, i.p., for the crotamine-negative venom (batch 2014CDU00201). The mixture of venoms for immunization was obtained by combining equal amounts of crotamine-positive and negative venoms.

The crotalic antivenom used in this study was produced at IVB (batches SAC085204b and SAC155204F), based on the guidelines of Brazilian Pharmacopeia, and the instructions of ANVISA $[5,21]$. This antivenom was of equine origin and consisted of purified $\left.\mathrm{F}(\mathrm{ab})_{2}\right)_{2}$ fragments. Antivenom SAC085204b, which expired in 2011, was from the same batch used in our previous antivenomics study [9]. The expiry date of the antivenom batch SAC155204F is October, 2018.

\section{RP-HPLC venom fractionation}

Venom composition was assessed by reversed-phase high-performance liquid chromatography (RP-HPLC) using a Shimadzu Prominence HPLC system. Pooled crotamine-positive (batch 2014CDU00301) and pooled crotamine-negative (batch 2014CDU00201) venom samples were resuspended in $200 \mu \mathrm{L}$ of $0.1 \%$ TFA and applied to a Teknokroma Europa $C_{18}$ column equilibrated with solvent A ( $0.1 \%$ trifluoroacetic acid - TFA). Bound proteins were eluted with discontinuous gradient of solvent B (0.1\% TFA in $100 \%$ of acetonitrile) at a flow rate of $1 \mathrm{~mL} / \mathrm{min}$. For RP-HPLC, we used the same gradient conditions applied in the previous proteomic characterization of $C$. $d$. terrificus [9]. The elution conditions were: isocratic at $5 \% \mathrm{~B}$ for $10 \mathrm{~min}$, followed by a 
gradient of $5-15 \%$ B for $20 \mathrm{~min}, 15-45 \%$ B for $120 \mathrm{~min}$ and $45-70 \%$ B for $20 \mathrm{~min}$, with a final isocratic step of $70 \% \mathrm{~B}$ for $5 \mathrm{~min}$. The elution profile was monitored at $214 \mathrm{~nm}$ in all experiments. Specific toxin families were identified by comparison of the chromatographic profile of each fraction with the RP-HPLC results from previous venomic analyses of $C$. $d$. terrificus $[8,9]$.

\section{Antivenomics}

A second-generation antivenomics method was used, as previously described by Pla et al. [17]. Briefly, $1 \mathrm{~mL}$ of NHS-activated Sepharose 4 Fast Flow resin (GE Healthcare) was washed with $10-15 \mathrm{~mL}$ of $1 \mathrm{mM} \mathrm{HCl}$ and then packed into a column. The column was equilibrated with $2 \mathrm{~mL}$ of coupling buffer (0.2 M NaHCO3, $0.5 \mathrm{M} \mathrm{NaCl}, \mathrm{pH}$ 9.3) at $\mathrm{pH} 7-8$. Fifty milligrams of $\mathrm{F}\left(\mathrm{ab}^{\prime}\right) 2$ fragments purified from crotalic antivenom was then loaded onto the column and incubated for $4 \mathrm{~h}$ at room temperature, according to the manufacturer's instructions. Unbound $F\left(a b^{\prime}\right) 2$ was washed from the column with equilibration buffer, collected and analyzed by SDS-PAGE. The amount of bound F(ab')2 was determined by quantifying the unbound antibody densitometrically after SDS-PAGE, using a standard curve obtained by loading known amounts of $\mathrm{F}\left(\mathrm{ab}^{\prime}\right)_{2}$ molecules $(1-5 \mu \mathrm{g})$ from the original antivenom. The efficiency of coupling (based on densitometric analysis) was $>90 \%$ for both antivenoms.

After the removal of unbound $F\left(a b^{\prime}\right) 2$, unreacted groups of the resin were blocked by incubation with $1 \mathrm{~mL}$ of $0.1 \mathrm{M}$ Tris- $\mathrm{HCl}, \mathrm{pH} 8.0$ on an orbital shaker, overnight at $22-25{ }^{\circ} \mathrm{C}$. The columns were subsequently washed alternately with three volumes of $0.1 \mathrm{M}$ acetate buffer/0.5 M NaCl, pH 4-5, and $0.1 \mathrm{M}$ Tris- $\mathrm{HCl}$, $\mathrm{pH}$ 8.5. This treatment was repeated six times.

Before incubation with the venoms, the columns were equilibrated with five volumes of phosphate-buffered saline (PBS). For the immunoassay, $300 \mu \mathrm{g}$ of $C$. d. terrificus venom, representing a venom:antivenom ratio of 1:150, was dissolved in $1 \mathrm{~mL}$ of PBS and applied to the column followed by incubation for $4 \mathrm{~h}$ at $25^{\circ} \mathrm{C}$ on an orbital shaker. After the incubation, the columns were washed five times with PBS and the unbound material was collected. Immunobound proteins were eluted with $5 \mathrm{~mL}$ of buffer (0.1 M glycine, $\mathrm{pH} 2.0)$, and neutralized with neutralization buffer (1 M Tris-HCI, pH 9.0). Venom proteins from the immunoaffinity column prepared with antivenom SAC085204b were fractionated by RP-HPLC using a Teknokroma Europa $C_{18}$ column on a Shimadzu Prominence HPLC system, whereas venom proteins from the immunoaffinity column prepared with antivenom SAC155204F were fractionated by RP-HPLC using a Shimadzu (10Avp) HPLC system. Proteins were eluted by washing the columns isocratically with $5 \% \mathrm{~B}$ for $5 \mathrm{~min}$, followed by a gradient of $5-25 \%$ B for $5 \mathrm{~min}$, $25-45 \% \mathrm{~B}$ for $60 \mathrm{~min}$ and $45-70 \%$ for $10 \mathrm{~min}$, with a final isocratic step of $70 \% \mathrm{~B}$ for $5 \mathrm{~min}$ at a flow rate of $1 \mathrm{~mL} / \mathrm{min}$. Protein detection was performed at $214 \mathrm{~nm}$.

\section{Results}

In a previous study, we reported that the antivenom raised against crotamine-negative $C$. $d$. terrificus venom failed to recognize crotamine in crotamine-positive venom [9]. To investigate the reason for this lack of immunoreactivity, the present study used a secondgeneration antivenomics protocol to assess the crossreactivity of a new batch of antivenom (SAC155204F) raised against a mixture of crotamine-positive and crotamine-negative venoms.

Initially, we antivenomics to confirm our previous finding regarding the lack of cross-reactivity between SAC085204b and crotamine. Figure 1 confirms the absence of immunoreactivity. To explore further the lack of immunoreactivity, we immunized horses with a mixture containing equal amounts of crotamine-positive and crotamine-negative venoms. Figure 2 shows the profiles of each venom type and the mixture of both. Based on comparison of the elution time of each fraction from RP-HPLC (Fig. 2) with the RP-HPLC results obtained during previous C.d. terrificus venomic characterization $[8,9]$, we identified the HPLC peaks as: 1 - crotamine, 2 - disintegrin, 3 - crotoxin acid chain, 4 to 7 - crotoxin basic chain, and 8 - low expressed toxins including D49-PLA 2 , serine protease (gyroxin), C-type lectin (convulxin) and PIII-metalloproteases.

Each batch of venom was obtained from specimens collected in the same geographical region as the populations of rattlesnakes were previously characterized by our venomics protocols [9]. Crotamine-positive venom (batch 2014CDU00301, $\mathrm{LD}_{50}=153 \mu \mathrm{g} / \mathrm{kg}$ ) was provided by NOPA and collected from 26 specimens of $C$. d. terrificus captured mainly in the state of Rio Grande do Sul (Fig. 2a). Crotamine-negative venom (batch 2014CDU00201, $\mathrm{LD}_{50}=73 \mu \mathrm{g} / \mathrm{kg}$ ) was provided by IVB and collected from 44 specimens found in the state of Minas Gerais (Fig. 2b).

The pooled venoms used in horse immunization were designed to provide a strong immune response against both crotamine and crotoxin (Fig. 3), and contained approximately $20 \%$ and $57 \%$ of these toxins, respectively (Fig. 2c). The data of antivenomics analysis clearly demonstrated immunoreactivity towards crotamine, as well as crotoxin, from both venom types (Fig. $3 \mathrm{~b}$ and e). Immunoreactivity was also observed against toxins that were expressed at lower concentrations and accounted for approximately $6 \%$ of the overall protein content of the immunizing pool (Fig. $3 \mathrm{c}$ and $\mathrm{f}$, fraction 8). This group of toxins, which includes D49-PLA 2 , serine 


\section{a}
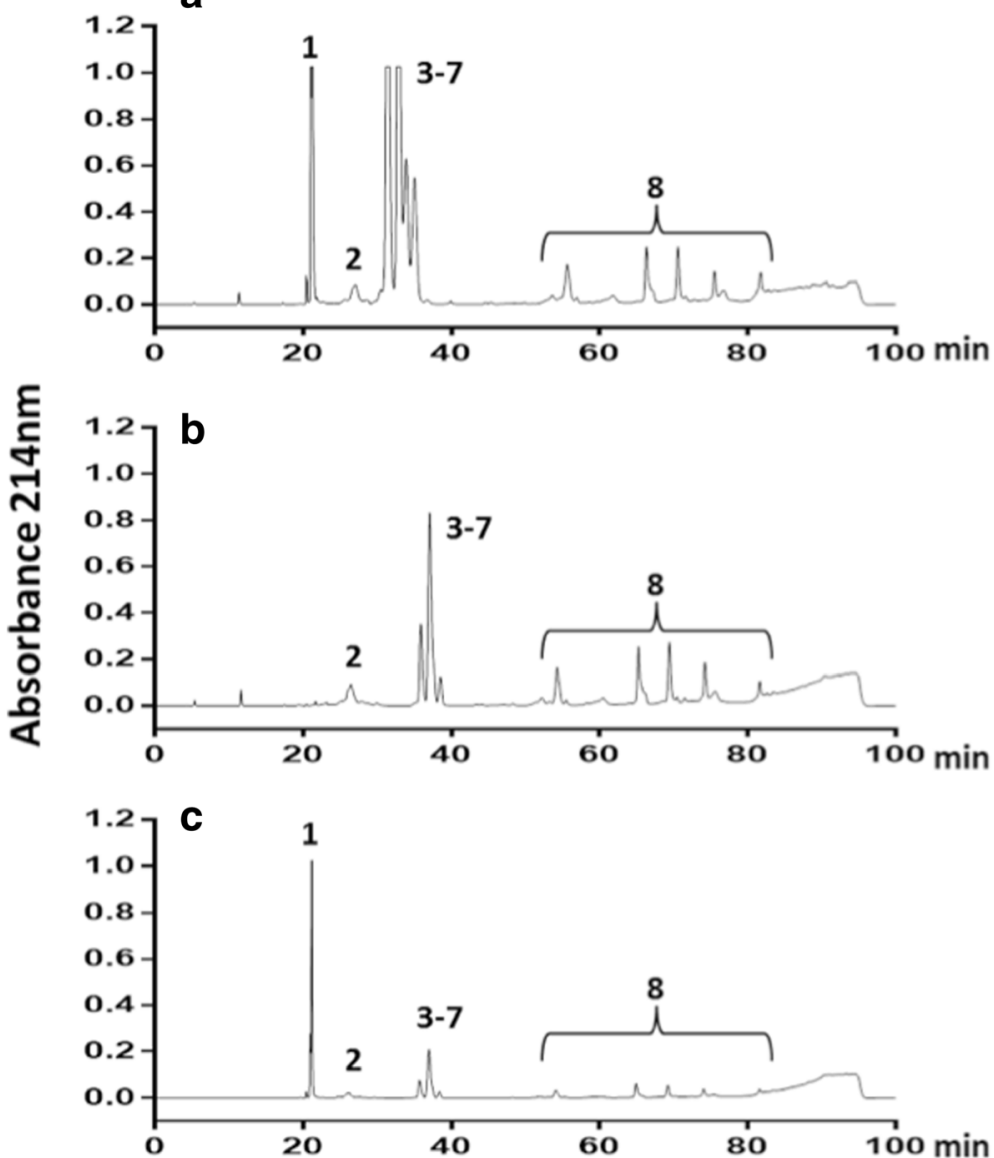

Fig. 1 Antivenomics analyses of crotalic antivenom manufactured by IVB. a About $300 \mu \mathrm{g}$ of crotamine-positive venom separated by RP-HPLC using second-generation antivenomics protocols [17]. The elution conditions were: isocratic gradient with $5 \%$ of $0.1 \%$ TFA in $100 \%$ of acetonitrile (solvent B) for 5 min followed by a 5-25\% B for 5 min, 25-45\% B for 60 min and 45-70\% B for 10 min, with a final isocratic step of $70 \%$ B for 5 min at a flow rate of $1 \mathrm{~mL} / \mathrm{min}$. $\mathbf{b}$ and $\mathbf{c}$ the RP-HPLC profiles of retained and non-retained venom toxins on anticrotalic (batch SAC085204b) affinity column, respectively. Protein families associated with HPLC peaks: 1 -crotamine, 2 - disintegrin, 3-7 - crotoxin, and 8 - fractions of low expression toxins including D49-PLA 2 , serine protease (gyroxin), C-type lectin (convulxin) and PIIl-metalloproteases

proteases (gyroxin) and P-III metalloproteases, is conserved in others subspecies of $C$. durissus $[8,9]$.

\section{Discussion}

Despite significant intraspecific venom variability, the beta-neurotoxin crotoxin is the main lethal component in $C$. durissus venom. Its $\mathrm{LD}_{50}$ values calculated in mice are between 60 and $180 \mu \mathrm{g} / \mathrm{kg}$, depending on the rout of administration (intravenous, subcutaneous etc.). Following crotalic envenomation, crotoxin is responsible for the neurotoxicity and local and systemic myotoxicity that leads to acute nephrotoxicity and renal failure [22-26]. On the other hand, the main effect of crotamine is to induce skeletal muscle spasms via interaction with $\mathrm{Na}^{+}$ channels [27, 28]. In animal models, crotamine also induces strong paralysis of the hind limbs [29].

Crotamine has a significantly lower toxicity $\left(\mathrm{LD}_{50}\right.$ $6.8 \mathrm{mg} / \mathrm{kg}$, i.e., two orders of magnitude higher than crotoxin) suggesting that it contributes more to prey immobilization than to lethality. However, crotamine has also been shown to contribute to myotoxic, cytotoxic and hemolytic activities that could potentially contribute to the nephrotoxicity often observed after envenomation by $C$. durissus [22, 26, 28, 30, 31]. Crotalic antivenom would be expected to neutralize crotamine and its activities. A major limitation of antivenom therapy after snakebite is that antivenoms with low neutralizing capacity must be administered at higher doses, with severe cases of envenomation requiring high amounts of antivenom [26]. Regarding the production and quality control of antivenoms, each batch must contain similar amount of IgG-derived molecules capable of neutralizing all of the toxic compounds in the venom of a certain specific species.

The venom $\mathrm{LD}_{50}$ values reported herein agree with the crotoxin/crotamine concentration for each type of 

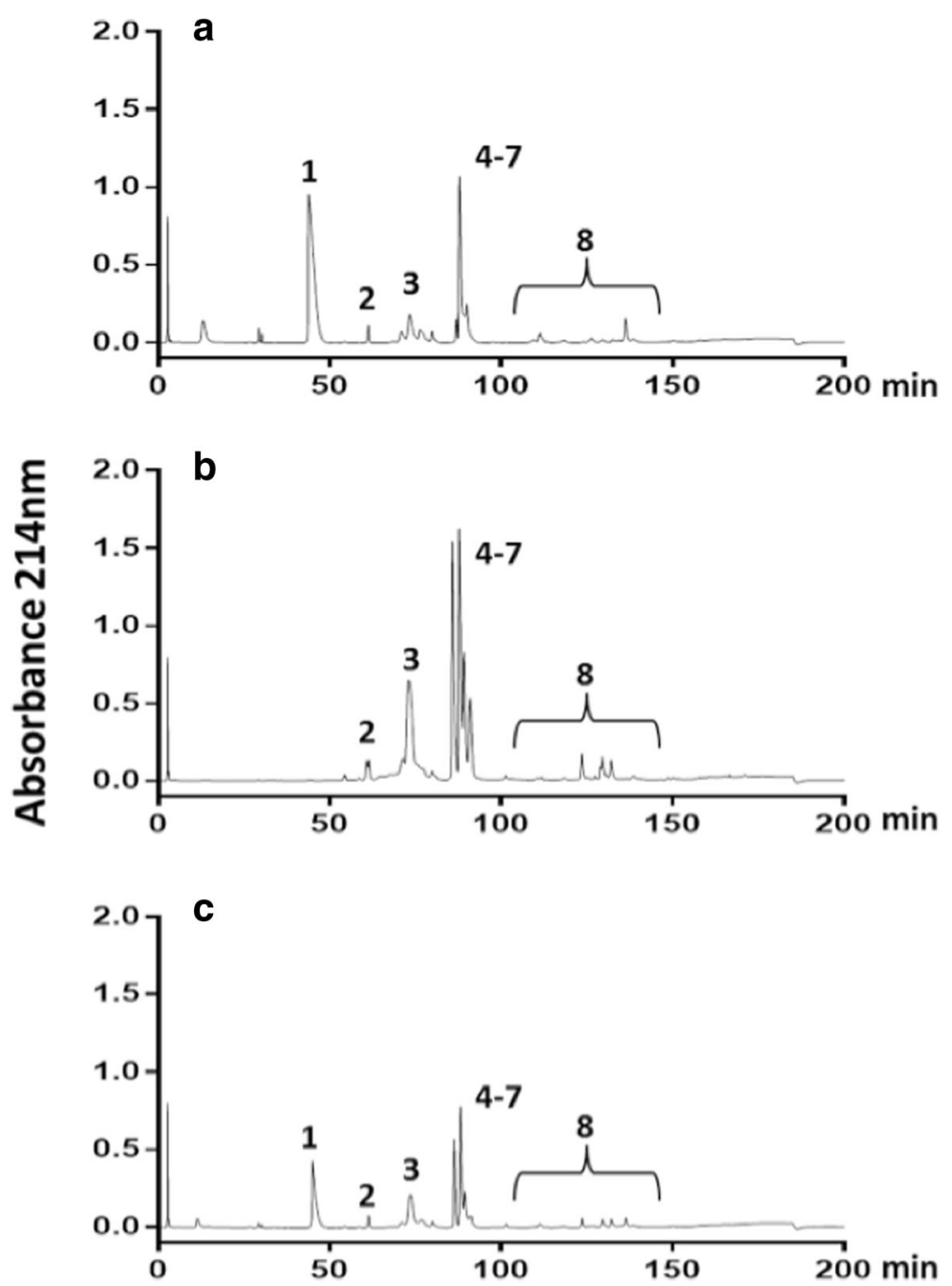

Fig. 2 Analyses of Crotalus durissus terrificus venoms by RP-HPLC. The venoms of C. d. terrificus (batches 2014CDU00301 and 2014CDU00201) were pooled from (a) crotamine-positive specimens collected in southern and (b) crotamine-negative specimens collected in southeastern Brazil, respectively. The pooled venom for immunization was obtained by combining (c) the same ratio of crotamine-positive and crotaminenegative venoms. The elution conditions were: isocratic gradient with $5 \%$ of $0.1 \%$ TFA in $100 \%$ of acetonitrile (solvent B for 10 min followed by $5-15 \%$ B for $20 \mathrm{~min}, 15-45 \%$ B for $120 \mathrm{~min}$ and $45-70 \%$ B for $20 \mathrm{~min}$, with a final isocratic step of 70\% B for $5 \mathrm{~min}$ at a flow rate of $1 \mathrm{~mL} /$ min. Protein families associated with HPLC peaks were: 1 - crotamine, 2 - disintegrin, 3 - crotoxin acid chain, 4 to 7 - crotoxin basic chain, and 8 - fractions of low expression toxins including D49-PLA 2 , serine protease (gyroxin), C-type lectin (convulxin) and PIII-metalloproteases

venom. The high content of crotoxin present in crotamine-negative venom likely explains the low $\mathrm{LD}_{50}$ value observed for this venom when compared to the $\mathrm{LD}_{50}$ of crotamine-positive venom. Although venom $\mathrm{LD}_{50}$ values may be similar, they provide little information about the overall venom composition since venoms often vary in their content of crotamine and other venom compounds (e.g., serine proteases, D49-PLA ${ }_{2 s}$, and metalloproteinases).

Although methods such as HPLC, SDS-PAGE and ELISA have been proposed to identify and quantify crotamine [32, 33], the ANVISA guidelines neither require standardization of the crotamine concentration in venom pools, nor do they propose any analytical method for the identification and quantification of this toxin. The current ANVISA regulation recommending the use of crotamine-positive venoms for immunization, without knowledge of the actual concentration of this compound in the venom, is problematic and can lead to fluctuations in antibody concentrations among batches.

The results presented in the current study show that the use of pools of venom with low crotamine content may stimulate a weak immune response for this molecule. In addition, crotamine-negative venoms may contain a greater amount of isoforms of the acidic chain of crotoxin, as well as other low expression toxins (Fig. 2b, 
$\mathbf{a}_{2}$

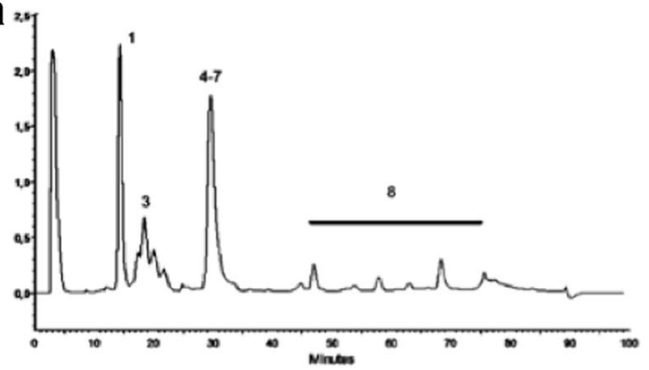

b

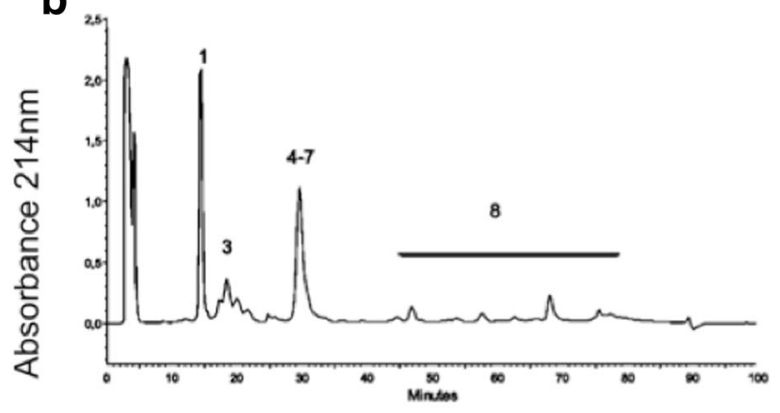

C

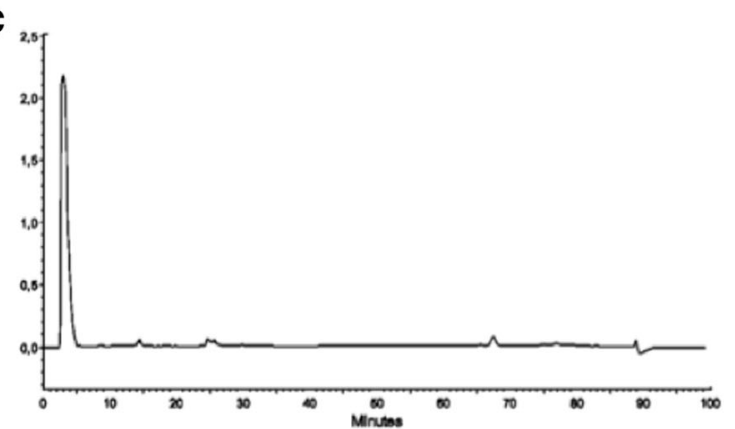

d

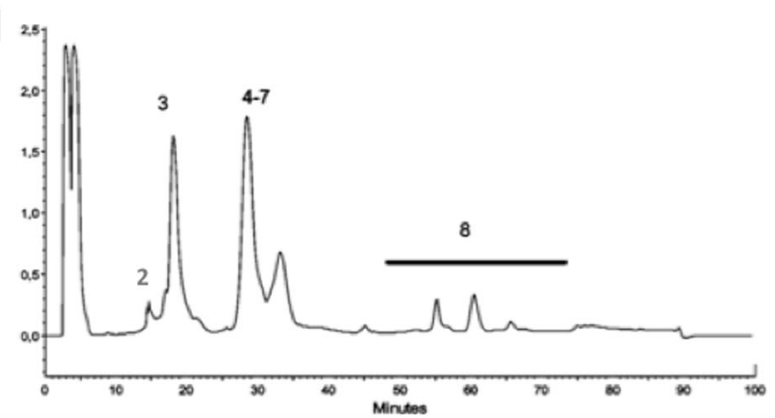

e

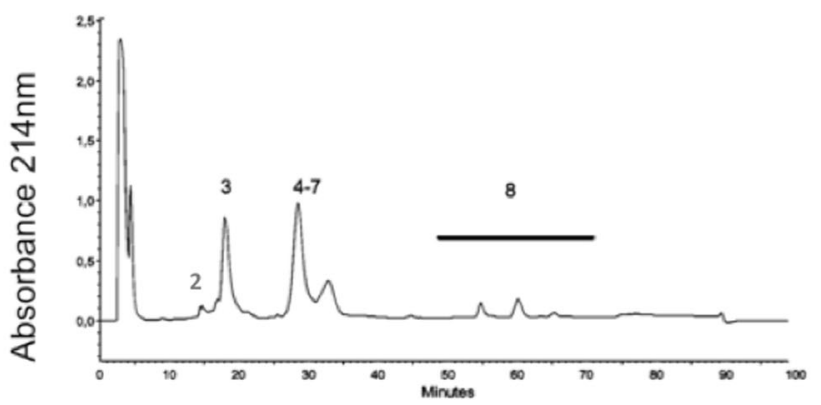

f

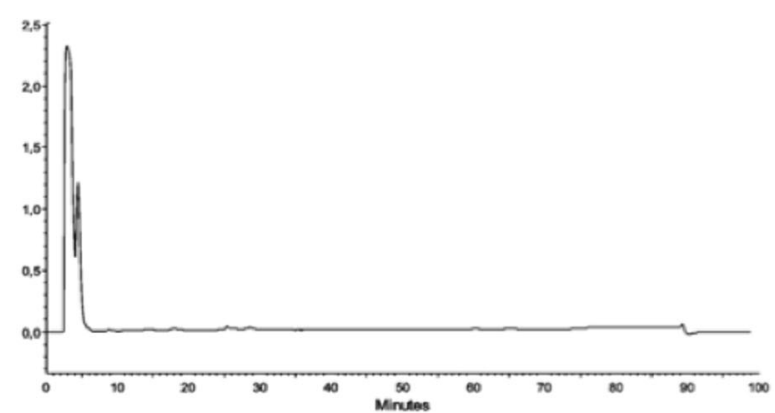

Fig. 3 Antivenomics analyses of crotalic antivenom manufactured by IVB from optimized venom mixture. a and $\mathbf{d}$ about $300 \mu \mathrm{g}$ of crotaminepositive and crotamine-negative venoms separated by RP-HPLC, respectively. $\mathbf{b}$ and $\mathbf{e}$ the RP-HPLC profiles of immunocaptured fractions of crotamine-positive and crotamine-negative venom from affinity column with crotalic antivenom SAC155204F (raised against a pool of both types of venoms), respectively. $\mathbf{c}$ and $\mathbf{f}$ the flow-through fraction of crotamine-positive and crotamine-negative venoms, respectively. The elution conditions were: isocratic gradient with $5 \%$ of $0.1 \%$ TFA in 100\% of acetonitrile (solvent B) for 5 min, followed by $5-25 \%$ B for 5 min, $25-45 \%$ B for $60 \mathrm{~min}, 45-70 \%$ B for $10 \mathrm{~min}$, with a final isocratic step of $70 \%$ B for $5 \mathrm{~min}$ at a flow rate of $1 \mathrm{~mL} / \mathrm{min}$. The first peak present in all chromatograms (elution time $3 \mathrm{~min}$ ) is a technical artifact. Protein families associated with HPLC peaks: 1 - crotamine, 2 - disintegrin, 3 - crotoxin acid chain 4 to 7 - crotoxin basic chain and 8 - fractions of low expression toxins including D49-PLA , serine protease (gyroxin), C-type lectin (convulxin) and PIII-metalloproteases

fractions 8), including D49-PLA 2 , a myotoxin that accounts for $18 \%$ of the venom proteome of the northeastern Brazilian rattlesnake C. d. cascavella [9]. Herein, we propose that the standardization of a minimal concentration of toxic compounds, especially crotamine and crotoxin in the $C$. $d$. terrificus venom pools used for immunization, is a valuable and necessary procedure to ensure quality and reproducibility among batches of crotalic antivenom from each manufacturing institution.

\section{Conclusions}

The results of the present study demonstrate the usefulness of antivenomics analyses for choosing the appropriate $C$. d. terrificus venoms for antivenom production. Our findings also show that by using a mixture containing equal amounts of crotamine-positive and crotamine-negative $C . d$. terrificus venoms, we were able to produce an equine antivenom that successfully recognized crotamine in crotamine-positive venom.

\section{Abbreviations}

ANVISA: National Health Surveillance Agency; FUNED: Ezequiel Dias Foundation; i.p.: Intraperitoneal; ICP: Clodomiro Picado Institute; IVB: Vital Brazil Institute; $\mathrm{LD}_{50}$ : Median lethal doses; NOPA: Regional Ophiology Center of Porto Alegre; PBS: Phosphate-buffered saline; PLA 2 : Phospholipase $A_{2} ;$ RPHPLC: Reversed-phase high-performance liquid chromatography;

TFA: Trifluoroacetic acid 


\section{Acknowledgments}

The authors gratefully acknowledge the Coordination for the Improvement of Higher Education Personnel (CAPES) thorough the Toxinology program (Edital 63/2010 process n. 2308.006277/2011-85) for all the support in this project. The authors wish to thank Dr. Anthony Saviola for reviewing the manuscript and Ms. Juliana Guzzo for technical support on experiments. Thanks are also due to the Center for the Study of Venoms and Venomous Animals (CEVAP) of UNESP for enabling the publication of this paper (Edital Toxinologia CAPES no. 063/2010, process no. 230.38.006285/2011-21, AUXPE Toxinologia 1219/2011).

\section{Funding}

The present work was supported by the National Council for Scientific and Technological Development (CNPq), Rio de Janeiro Research Foundation (FAPERJ) and by the Edital Toxinologia CAPES no. 063/2010, Process no. 2308.006277/2011-85, AUXPE 1517/2011.

\section{Authors' contributions}

RTA participated in data collection and experimental design. PC, LBM and FP participated in data collection. MLA and MLMA supervised the collection of Crotalus venom. RBZ controlled the experiments, interpreted results and reviewed the article. CCN performed data collection, experimental design, interpreted results, wrote the article draft, reviewed and edited the article. All authors read and approved the final manuscript.

\section{Competing interests}

The authors declare that they have no competing interests.

\section{Consent for publication}

Not applicable.

\section{Ethics approval and consent to participate}

Not applicable.

\section{Publisher's Note}

Springer Nature remains neutral with regard to jurisdictional claims in published maps and institutional affiliations.

\section{Author details}

'Laboratório de Hemostase e Venenos, Instituto de Bioquímica Médica Leopoldo de Meis, Universidade Federal do Rio de Janeiro (UFRJ), Rio de Janeiro, RJ, Brasil. Departamento de Antígenos e Cultivo Celular, Instituto Vital Brazil, Niterói, RJ, Brasil. ${ }^{3}$ Núcleo Regional de Ofiologia de Porto Alegre (NOPA), Museu de Ciências Naturais, Fundação Zoobotânica do Rio Grande do Sul, Avenida Dr. Salvador França, 1427, Porto Alegre, RS, Brasil.
\end{abstract}

\section{Received: 22 December 2016 Accepted: 5 May 2017}

\section{Published online: 12 May 2017}

\section{References}

1. Calvete JJ. Proteomic tools against the neglected pathology of snake bite envenoming. Expert Rev Proteomics. 2011;8(6):739-58.

2. Gutiérrez JM, Lomonte B, Sanz L, Calvete JJ, Pla D. Immunological profile of antivenoms: preclinical analysis of the efficacy of a polyspecific antivenom through antivenomics and neutralization assays. J Proteomics. 2014;105:340-50.

3. Melgarejo AR. Serpentes peçonhentas do Brasil. In: Cardoso JLC, França FOS, Wen FH, Málaque CMS, Haddad JV, editors. Animais peçonhentos no Brasil: biologia, clínica e terapêutica dos acidentes. São Paulo: Sarvier; 2003. p. 33-61.

4. Costa HC, Bérnils RS. Répteis brasileiros: lista de espécies. Herpetologia Brasileira. 2014;4:74-84.

5. Ministério da Saúde. Normas técnicas de produção e controle de qualidade de soros, Portaria no 174 - Agência Nacional de Vigilância Sanitária. 1996.

6. Francischetti IM, Gombarovits ME, Valenzuela JG, Carlini CR, Guimarães JA. Intraspecific variation in the venoms of the South American rattlesnake (Crotalus durissus terrificus). Comp Biochem Physiol C Toxicol Pharmacol. 2000;127(1):23-36.

7. Saravia P, Rojas E, Arce V, Guevara C, López JC, Chaves E, et al. Geographic and ontogenic variability in the venom of the neotropical rattlesnake
Crotalus durissus: pathophysiological and therapeutic implications. Rev Biol Trop. 2002;50(1):337-46.

8. Calvete JJ, Sanz L, Cid P, de la Torre P, Flores-Díaz M, Dos Santos MC, et al. Snake venomics of the Central American rattlesnake Crotalus simus and the South American Crotalus durissus complex points to neurotoxicity as an adaptive paedomorphic trend along Crotalus dispersal in South America. J Proteome Res. 2010;9(1):528-44.

9. Boldrini-França J, Corrêa-Netto C, Silva MM, Rodrigues RS, De La Torre P, Pérez A, et al. Snake venomics and antivenomics of Crotalus durissus subspecies from Brazil: assessment of geographic variation and its implication on snakebite management. J Proteomics. 2010;73(9):1758-76.

10. Cavalcante WL, Ponce-Soto LA, Marangoni S, Gallacci M. Neuromuscular effects of venoms and crotoxin-like proteins from Crotalus durissus ruruima and Crotalus durissus cumanensis. Toxicon. 2015;96:46-9.

11. Schenberg S. Geographical pattern of crotamine distribution in the same rattlesnake subspecies. Science. 1959;129(3359):1361-3.

12. Oguiura N, Collares MA, Furtado MF, Ferrarezzi H, Suzuki H. Intraspecific variation of the crotamine and crotasin genes in Crotalus durissus rattlesnakes. Gene. 2009;446(1):35-40.

13. Lourenço Jr A, Zorzella Creste CF, de Barros LC, Delazari dos Santos L, Pimenta DC, Barraviera B, et al. Individual venom profiling of Crotalus durissus terrificus specimens from a geographically limited region: crotamine assessment and captivity evaluation on the biological activities. Toxicon. 2013;69:75-81.

14. Lomonte B, Escolano J, Fernández J, Sanz L, Angulo Y, Gutiérrez JM, et al. Snake venomics and antivenomics of the arboreal neotropical pitvipers Bothriechis lateralis and Bothriechis schlegelii. J Proteome Res. 2008;7(6):2445-57.

15. Núñez V, Cid P, Sanz L, De La Torre P, Angulo Y, Lomonte B, et al. Snake venomics and antivenomics of Bothrops atrox venoms from Colombia and the Amazon regions of Brazil, Perú and Ecuador suggest the occurrence of geographic variation of venom phenotype by a trend towards paedomorphism. J Proteomics. 2009;73(1):57-78.

16. Calvete JJ, Borges A, Segura A, Flores-Díaz M, Alape-Girón A, Gutiérrez JM, et al. Snake venomics and antivenomics of Bothrops colombiensis, a medically important pitviper of the Bothrops atrox-asper complex endemic to Venezuela: Contributing to its taxonomy and snakebite management. J Proteomics. 2009;72(2):227-40.

17. Pla D, Gutiérrez JM, Calvete JJ. Second generation snake antivenomics: Comparing immunoaffinity and immunodepletion protocols. Toxicon. 2012;60(4):688-99.

18. Gutiérrez JM, Lomonte B, León G, Alape-Girón A, Flores-Díaz M, Sanz L, et al Snake venomics and antivenomics: Proteomic tools in the design and control of antivenoms for the treatment of snakebite envenoming. J Proteomics. 2009;72(2):165-82.

19. Calvete JJ, Sanz L, Angulo Y, Lomonte B, Gutiérrez JM. Venoms, venomics, antivenomics. FEBS Lett. 2009;583(11):1736-43.

20. Calvete JJ. Antivenomics and venom phenotyping: A marriage of convenience to address the performance and range of clinical use of antivenoms. Toxicon. 2010;56(7):1284-91.

21. Agência Nacional de Vigilância Sanitária. Farmacopeia Brasileira. Brasília. $5^{a}$ Edição. 2010. http://portal.anvisa.gov.br/documents/33832/260079/ 5\%C2\%AA+edi\%C3\%A7\%C3\%A3o+-+Volume+1/4c530f86-fe83-4c4ab907-6a96b5c2d2fc

22. Gutiérrez JM, Cerdas L. Mechanism of action of myotoxins isolated from snake venoms. Rev Biol Trop. 1984;32(2):213-22 [Article in Spanish].

23. Amora DN, Souza TM, Martins AMC, Barbosa PSF, Magalhães MR, Toyama $\mathrm{MH}$, et al. Effects of Crotalus durissus collilineatus venom in the isolated rat kidney. Toxicon. 2006;47(3):260-4.

24. Bon C, Bouchier C, Choumet V, Faure G, Jiang MS, Lambezat MP, et al. Crotoxin, half-century of investigations on a phospholipase $A_{2}$ neurotoxin. Acta Physiol Pharmacol Latinoam. 1989;39(4):439-48.

25. Sampaio SC, Hyslop S, Fontes MRM, Prado-Franceschi J, Zambelli VO, Magro AJ, et al. Crotoxin: novel activities for a classic $\beta$-neurotoxin. Toxicon. 2010;55:1045-60.

26. Pinho FMO, Zanetta DMT, Burdmann EA. Acute renal failure after Crotalus durissus snakebite: a prospective survey on 100 patients. Kidney Int. 2005; 67(2):659-67.

27. Chang CC, Tseng KH. Effect of crotamine, a toxin of South American rattlesnake venom, on the sodium channel of murine skeletal muscle. $\mathrm{Br}$ J Pharmacol. 1978;63(3):551-9. 
28. Oguiura N, Boni-Mitake M, Rádis-Baptista G. New view on crotamine, a small basic polypeptide myotoxin from South American rattlesnake venom. Toxicon. 2005;46(4):363-70.

29. Brazil OV, Prado-Franceschi J, Laure CJ. Repetitive muscle responses induced by crotamine. Toxicon. 1979;17(1):61-7.

30. Ministério da Saúde. Manual de diagnóstico e tratamento de acidentes por animais peçonhentos. 2nd ed. Braślia: Fundação Nacional de Saúde; 2001. http://bvsms.saude.gov.br/bvs/publicacoes/funasa/manu_peconhentos.pdf.

31. Oguiura N, Boni-Mitake M, Affonso R, Zhang G. In vitro antibacterial and hemolytic activities of crotamine, a small basic myotoxin from rattlesnake Crotalus durissus. J Antibiot (Tokyo). 2011;64(4):327-31.

32. Oguiur N, Camargo ME, da Silva AR, Horton DS. Quantification of crotamine, a small basic myotoxin, in South American rattlesnake (Crotalus durissus terrificus) venom by enzyme-linked immunosorbent assay with paralle-lines analysis. Toxicon. 2000:38(3):443-8.

33. de Oliveira SA, Magalhães MR, Salazar VC, Valadares MC, da Cunha LC. Identification of crotamine in the venom of Crotalus durissus collilineatus by three different methods. Toxicon. 2015;95:46-51.

Submit your next manuscript to BioMed Central and we will help you at every step:

- We accept pre-submission inquiries

- Our selector tool helps you to find the most relevant journal

- We provide round the clock customer support

- Convenient online submission

- Thorough peer review

- Inclusion in PubMed and all major indexing services

- Maximum visibility for your research

Submit your manuscript at www.biomedcentral.com/submit
C Biomed Central 